physicians and regulatory bodies can play a vital role in achieving this goal. It is now time to stop promises and to start practices in order to achieve the premium health status that will be beneficial for all.

\section{Fahad Saleem,}

Universiti Sains Malaysia, Pharmaceutical

Sciences, Jalan Sungai Dua, Penang, 11800,

Malaysia. E-mail: fahaduob@gmail.com

Jalan Sungai Dua,

Universiti Sains Malaysia, Pharmaceutical

Sciences, Penang, Malaysia.

Azmi Ahmad Hassali,

Universiti Sains Malaysia, Pharmaceutical

Sciences, Penang, Malaysia.

Asrul Akmal Shafie,

Universiti Sains Malaysia, Pharmaceutical

Sciences, Penang, Malaysia.

\section{REFERENCES}

1. Kannel WB. Blood pressure as a cardiovascular risk factor. J Am Med Assoc 1996; 275(20): 1571-1576.

2. Kearney PM, Whelton M, Reynolds K, et al. Global burden of hypertension: analysis of worldwide data. Lancet 2005; 365(9455): 217-223.

3. Kearney P, Whelton M, Reynolds K, et al. Worldwide prevalence of hypertension: a systematic review. J Hypertens 2004; 22(1): 11-19.

4. Sailesh M, Norm RCC. Hypertension management: time to shift gears and scale up national efforts. Hypertension 2009; 53(3): 450-451.

5. Sarafidis PA, Li S, Chen SC, et al. Hypertension awareness, treatment, and control in chronic kidney disease. Am J Med 2008; 121(4): 332-340.

6. Anonymous. $18 \%$ population suffering from hypertension. The Daily Times. http://www.dailytimes.com.pk/default.asp?page=sto y_28-3-2005_pg7_32 (accessed 11 May 2010)

7. Azhar S, Hassali MA, Ibrahim MI, et al. The role of pharmacists in developing countries: the current scenario in Pakistan. Hum Res Health 2009; 7: 54.

8. WHO. Health system profile. Egypt: Regional Health System Observatory, 2006.

9. Hashmi SK, Afridi MB, Abbas K, et al. Factors associated with adherence to anti-hypertensive treatment in Pakistan. PLoS One 2007; 2(3): e280.

DOI: 10.3399/bjgp10X502182

\section{Incapacity certification}

I was delighted to read the April Focus in the BJGP. ${ }^{1}$ The new more positive approach to certification of incapacity is to be welcomed. Starting in 1947 , whenever I issued a 'certificate' I gave an expected duration of incapacity. This enabled both patient and employer to anticipate 'return to full function'. It also led the patient to realise that they had a duty to 'get better'. My patients always knew I was not a soft touch for extended sloth.

PS. I still feel strongly at 90 .

Roy Webb,

Green Gables, Kersey, Suffolk, IP7 6EB.

\section{REFERENCE}

1. Jones R. Challenges to advocacy in primary health care. Br J Gen Pract 2010; 60(573): 234.

DOI: 10.3399/bjgp10X502191

\section{Automated electronic reminders and primary prevention of cardiovascular disease}

Holt et al present interesting data on the effect of automated electronic prompts on primary prevention of cardiovascular disease.

Their results support recent anecdotal observations I made while trying to achieve the yearly cardiovascular disease (CVD)/cornary heart disease (CHD) QOF targets for one of the local practices in Fulham.

It is interesting to see these observations corroborated by a well conducted randomised controlled trial.

In contrast to the EMIS software used in their study, our practice uses VISION software that has a built in CVD/CHD risk calculator based on the Framingham risk equation applied to the most recent risk factor measurements.

Each patient's CVD/CHD risk is immediately visible in the lower left-hand corner of the computer screen. Clicking on the reported risk score releases a popup window containing the risk calculator and recent measurements of risk factors such as smoking, cholesterol, and blood pressure, presenting the opportunity to address unmet QOF targets and control clinical parameters.

Translating identified risk and appropriate interventions into improved clinical outcomes is the bigger challenge, and one clear potential implication from

Holt et al's study is that high QOF CVD/CHD scores may not necessarily result in reduction in cardiovascular event rates.

The reasons for this are not clear and are probably multifactorial, however, poor patient understanding of CVD/CHD risk and risk reduction is contributory and can be partly addressed by using the $\mathrm{CVD} / \mathrm{CHD}$ risk calculator interactively during consultations.

This can be done by demonstrating to the patient how his or her risk can increase or decrease with positive or negative changes in the measurements of clinical parameters. Therefore, the CVD/CHD risk calculator can also be a powerful tool used to build therapeutic relationships and improve understanding of CVD/CHD risk and what it means for each patient on a personal level.

\section{Ayokunle Abegunde,}

The New Surgery, 128 Canterbury Road,

Folkestone, CT19 5SR.

E-mail: Rabegs@doctors.org.uk

\section{REFERENCE}

1. Holt TA, Thorogood M, Griffiths F, et al. Automated electronic reminders to facilitate primary cardiovascular disease prevention: randomised controlled trial. Br J Gen Pract 2010; 60(573): 251-256.

DOI: 10.3399/bjgp10X502209

\section{Near-patient testing holds most promise for acute conditions}

We welcome the editorial by Professor Khunti on near-patient testing in general practice. ${ }^{1}$ He states that quality assurance is of utmost importance if near-patient testing is to be successfully implemented in general practice. We fully agree on this 